\title{
Interação social de crianças cegas e de crianças videntes na educação infantil
}

\author{
Maria Luiza Pontes de França-Freitas \\ Maria Stella Coutinho de Alcântara Gil
}

\section{Resumo}

As interações de crianças cegas têm sido objeto de crescente interesse nas últimas décadas. Diante disso, os objetivos desse estudo, propostos em classes inclusivas da Educação Infantil, foram: caracterizar a interação social de crianças cegas que receberam ou não estimulação constante e especializada; e caracterizar a interação social de crianças cegas e videntes. Participaram duas crianças cegas com aproximadamente cinco anos e seus colegas de sala regular. Foram organizadas situações em que as crianças pudessem brincar, e seus desempenhos foram videogravados. Foi adotado um sistema de classificação que permitiu a análise comparativa das interações dos participantes e utilizado o SPSSWIN (13.0) para realizar as análises estatísticas. Foram encontradas semelhanças e diferenças significativas ao comparar as características das interações das crianças cegas com as das videntes. Foi possível verificar que, havendo estimulação constante e especializada, a criança cega apresenta comportamentos semelhantes aos de uma criança vidente no ambiente escolar.

Palavras-chave: Interação social, cegueira, brincadeiras.

\section{Social interaction of blind children and sighted children in early childhood education}

\begin{abstract}
Blind children' interactions have been the subject of increasing interest in recent decades. Therefore, the main objectives of this study, proposed to inclusive kindergarten, is to characterize the social interaction of blind children who either received or not a specialized and constant stimulation. We intend to characterize the social interaction of blind children with those who can see Two blind children with approximately five years old and their classmates participated in the research. We organized situations in which children could play. Their performances were videotaped. The classification system used allowed the comparative analysis of the interactions of the participants and was adopted the SPSS-WIN (13.0) for data analysis. We found similarities and differences when compared characteristics of the interactions between blind children with those of the seers. When there is constant stimulation the blind children have a behavior similar to those of children who see.
\end{abstract}

Keywords: Social interaction, blindness, tricks.

\section{Interacción social de niños ciegos y de niños videntes de educación infantil}

\section{RESUMEM}

La interacción de niños ciegos ha sido objeto de creciente interés en las últimas décadas. Los objetivos de este estudio fueron propuestos en aulas inclusivas de Educación Infantil y fueron: caracterizar la interacción social de niños ciegos que recibieron o no estimulación constante y especializada; y caracterizar la interacción social de niños ciegos y videntes. Participaron dos niños ciegos con aproximadamente cinco años y sus compañeros de sala regular. Se organizaron situaciones en que los niños pudiesen jugar y sus desempeños fueron grabados en video. Se adoptó un sistema de clasificación que permitió el análisis comparativo de las interacciones de los participantes y se utilizó el SPSS-WIN (13.0) para realizar los análisis estadísticos. Se encontraron semejanzas y diferencias significativas al comparar las características de las interacciones entre los niños ciegos con la interacción entre niños ciegos y videntes. Fue posible verificar que habiendo estimulación constante y especializada el niño ciego presenta comportamientos semejantes a los de un niño vidente en ambiente escolar.

Palabras Clave: interacción social; niños ciegos; juegos. 


\section{Introdução}

As interações que ocorrem entre crianças têm sido objeto de crescente interesse nas últimas décadas. No caso de crianças com deficiência visual, o estudo dessa temática torna-se ainda mais relevante, pois a limitação visual impõe dificuldades que interferem na interação social (D'Allura, 2002; Gold, Shaw, \& Wolffe, 2010; Santos, 2004), particularmente em interações com colegas videntes (Brambring, 2001).

Para Erwin (1993), algumas das dificuldades encontradas pelas crianças com deficiência visual nas interações sociais são: dificuldade em interpretar mensagens não verbais e monitorar seu próprio comportamento durante encontros sociais e ter poucas oportunidades para interagir com os pares. Kekelis (1997) destaca que a falta de oportunidades para se engajar nas relações com os colegas, como fazem as crianças videntes, é uma das principais dificuldades de interação das crianças com deficiência visual. A restrição de oportunidades pode resultar de diversos aspectos como, por exemplo: os problemas associados à mobilidade que ocasiona contatos sociais limitados (Erwin, 1993) e o fato de alguns pais das crianças cegas não encorajarem a interação delas com os colegas e superprotegerem os filhos, evitando situações de interação com os pares (Kekelis, 1997). A postura excessivamente protetora dos pais prejudica as oportunidades da criança com deficiência visual de se engajar nas relações com os colegas e afeta o desenvolvimento de modos apropriados de interação com os seus pares. As reações parentais em relação à criança deficiente visual têm, portanto, implicações para o ambiente ao qual a criança está exposta, bem como no encorajamento para se engajar nele (Warren, 1994). Pais reagem de várias formas e essas variações afetam o ambiente no qual a criança se desenvolve.

As dificuldades em se inserir em grupos de interação entre crianças tornam-se mais perceptíveis quando a criança cega começa a frequentar a escola. De acordo com Brambring (2001), depois do terceiro ano de idade, a criança cega tem dificuldades maiores em se ajustar à pré-escola, e algumas dessas dificuldades persistem ao longo dos anos. $\mathrm{O}$ autor verificou, por exemplo, que brincadeiras individuais de crianças cegas e videntes podiam ser observadas em situações de brincadeiras não estruturadas. Até mesmo em atividades semiestruturadas, como desenhar ou fazer trabalhos manuais, eram raras as brincadeiras cooperativas entre crianças cegas e seus colegas videntes. Crocker e Orr (1996) ressaltam que as deficiências sensoriais podem afetar não apenas as oportunidades de interação das crianças, mas também a natureza da interação. Numa perspectiva comparativa, esses autores, com o objetivo de investigar as interações das crianças cegas em vários ambientes da pré-escola, utilizaram o Behaviour Observation Record, ou seja, registro de observação de comportamento para comparar as interações sociais de nove crianças com deficiência visual e nove crianças videntes. Algumas dessas crianças, nos dois grupos, também apresentavam outras deficiências, como paralisia cerebral e atraso de desenvolvimento. Os autores empregaram um sistema descritivo com quatro categorias de desempenho para analisar as interações sociais entre a criança designada (deficiente visual ou vidente) e seus colegas e professores. Cada categoria foi decomposta em quatro subcategorias: Condição antecedente (sozinho, com professor, com um ou dois colegas, e em um grupo); Iniciador; Receptor; Tipo de comunicação. Os resultados indicaram que as crianças com deficiência visual interagiam com os outros. No entanto, foram observadas diferenças tanto na frequência com que elas iniciaram uma interação e receberam uma iniciativa, como nos alvos (professor ou colegas) das iniciativas de suas interações. Na maior parte das ocorrências, as crianças com deficiência visual foram mais receptoras do que iniciadoras de uma interação, bem como iniciaram mais interações com o professor do que com crianças videntes.

Do número total de interações registradas para cada grupo de crianças, Crocker e Orr (1996) verificaram que as crianças videntes tinham duas vezes mais probabilidade de iniciar uma interação do que tinham as crianças com deficiência visual. Embora as iniciativas das crianças videntes fossem igualmente dirigidas para um professor ou colega, as iniciativas das crianças deficientes visuais tinham duas vezes mais probabilidade de serem dirigidas para o professor.

Quando se trata de uma criança cega com deficiências adicionais, outras dificuldades nas interações sociais podem ser observadas. O estudo de caso desenvolvido por Celeste (2006) teve como objetivo descrever comportamentos de brincadeira e interações sociais de uma criança cega com deficiências adicionais. Essa criança foi submetida desde os quatro meses de idade a serviços de intervenção precoce que estimulavam seu desenvolvimento social, motor e sua orientação e mobilidade. O método de avaliação incluiu análises do desenvolvimento e adaptativas, observação de brincadeiras estruturadas e entrevistas com pais, colegas, professores e cuidadores. A participante apresentou comportamento de brincadeira limitado e interações sociais comprometidas, considerando-se que a maioria de suas interações não apenas foram breves, mas foram encerradas pelas outras crianças. No ambiente da creche, a participante passou a maior parte do tempo só. Essa criança permaneceu grande parte do tempo total em que foi observada engajada em brincadeiras denominadas de "não sociais", ou seja, brincando sozinha, e apenas $20 \%$ do tempo em brincadeiras sociais, ou seja, brincando com outras crianças. Um aspecto que chamou atenção nesse estudo foi que, ao contrário do que a literatura apresenta (por exemplo, Erwin, 1993), a participante engajou-se em jogos de papéis (jogos dramáticos) altamente imaginativos (sozinha ou com outras crianças). Do mesmo modo que Celeste (2006), Hueara, Souza, Batista, Melgaço e Tavares (2006) afirmam que, durante as situações de brincadeira, as crianças com deficiência visual podem apresentar grande capacidade de representar papéis. 
Erwin (1993) também examinou, por meio de observações diretas e registros em vídeo, a participação social de 28 crianças com deficiência visual, entre 36 e 67 meses, durante períodos de brincadeira livre em ambientes educacionais naturais. Algumas dessas crianças apresentavam deficiências adicionais, como, por exemplo, deficiência intelectual. Os resultados indicaram que crianças com deficiência visual e deficiências associadas não brincavam, e aquelas sem deficiências adicionais engajavam-se em brincadeiras solitárias.

Brambing (2001) destaca que algumas crianças cegas podem encontrar dificuldades para expressar afeição à outra criança e rejeitam interações propostas pelos colegas videntes. A análise realizada por Celeste (2006) indicou que algumas dessas crianças recebem poucas respostas positivas pelas ofertas ou tentativas de se engajar em interações sociais com os colegas videntes. Isso pode resultar na diminuição do interesse por seus pares e torna as crianças cegas mais propensas ao isolamento (Ajuwon \& Oyinlade, 2008).

A despeito das possíveis dificuldades encontradas pelas crianças cegas nas relações com seus pares, vários autores concordam com a relevância das interações entre crianças cegas e videntes para o desenvolvimento global e o desenvolvimento da sociabilidade em especial (Celeste, 2007; Gold e cols., 2010; Roe, 2008; Warren, 1994). Para as crianças com deficiência visual, a interação com os outros é fundamental para superar algumas das limitações de acesso visual que essas crianças experienciam, bem como para ajudá-las a fazer conexões e desenvolver sua compreensão do mundo (Roe, 2008).

Para Bruno (1993), a criança com deficiência visual necessita do relacionamento com crianças videntes e não videntes de sua idade para que possa construir sua própria identidade, ao confrontar semelhanças e diferenças. A autora afirma que as interações podem contribuir para a construção da própria imagem corporal da criança cega, além de fornecer oportunidades de testar suas hipóteses perceptivas, simbólicas e lógicas, representando suas experiências no tempo e no espaço, através da ação e da linguagem dirigida ao outro. Roe (2008) também enfatiza que crianças com deficiência visual precisam de oportunidades para interagir com uma ampla gama de colegas, incluindo aqueles com um elaborado repertório de habilidades sociais e de comunicação, pois esses colegas podem servir de modelos positivos e compensar alguns dos desafios criados pelo acesso limitado às informações visuais.

Ao tratar da interação social das crianças cegas com as crianças videntes, Warren (1994) enfatiza três aspectos a serem levados em conta: as habilidades sociais da criança cega, as reações do colega e o papel dos adultos. As habilidades sociais precisam ser aprendidas pelas crianças cegas para facilitar sua interação efetiva com os colegas videntes. Seria importante avaliar a variedade de habilidades sociais de crianças cegas e formas de interação e determinar como essas variações afetam as reações dos colegas. Além disso, o papel dos adultos influencia de modo crescente o desenvolvimento social da criança. A mediação do adulto é fundamental, pois, em situações de interação social entre crianças cegas e videntes, poderá intervir para reforçar as iniciativas de interação das crianças cegas, bem como para auxiliá-las na expressão da afetividade.

Os estudos citados ressaltaram diferenças e semeIhanças ao comparar as interações de crianças cegas com crianças videntes, uma abordagem adotada e valorizada em muitos estudos (Warren, 1994). A tendência dos estudos contemporâneos, entretanto, é destacar a importância do enfoque diferencial quando são avaliados comportamentos e o desenvolvimento de crianças com deficiência visual. Warren (1994) defendeu o emprego da abordagem diferencial, porém sem descartar algumas vantagens da comparação entre populações.

Na confluência das propostas comparativa e diferencial, outra perspectiva pode ser atendida, considerando-se que a comparação entre os desempenhos de crianças cegas e videntes associada à comparação entre crianças cegas pode contribuir para levantar possíveis variáveis implicadas nas semelhanças e diferenças intra e entre populações.

Ao se comparar os comportamentos de crianças cegas com os de crianças videntes, o enfoque comparativo é priorizado, com destaque para a ausência ou presença da visão e suas implicações. Como destaca Leme (2003), na comparação com crianças videntes, não se ressalta aquilo de que a criança cega é capaz. Optando por realçar o potencial da criança com deficiência visual, o enfoque diferencial pode ser considerado mais vantajoso, pois possibilita gerar conhecimentos que podem contribuir para a intervenção ao considerar as circunstâncias que otimizam o desenvolvimento das crianças cegas (Warren, 1994).

A conjunção das análises que atendem aos enfoques comparativo e diferencial, entretanto, pode ser uma estratégia frutífera para caracterizar o desenvolvimento das competências sociais da vida escolar de crianças com deficiência visual em um período específico. Comparar os desempenhos de crianças cegas e videntes e entre crianças cegas pode contribuir tanto para que se identifiquem as características comuns das crianças, independentemente das condições de acesso visual à informação, como para identificar as peculiaridades de desempenho e possíveis relações com história de vida ou com os contextos de desenvolvimento e escolarização. Permite o acesso às características comuns tanto às crianças cegas entre si, como delas com as crianças com desenvolvimento típico; simultaneamente, permite conhecer características que as diferenciam e particularizam, sem tomar o desenvolvimento da criança vidente como norma.

Diante das considerações expostas, os objetivos desse estudo foram: (a) caracterizar a interação social de crianças cegas que receberam ou não estimulação constante e especializada; e (b) caracterizar a interação social de crianças cegas e videntes. 


\section{Participantes}

Participaram deste estudo duas crianças cegas do sexo masculino com aproximadamente cinco anos de idade e seus colegas de sala matriculados em sala de aula regular de escolas públicas localizadas em duas cidades do interior de São Paulo. O número total de crianças videntes em ambas as instituições foi trinta e um, a maioria do sexo feminino (55\%), com idades que variaram de três a seis anos.

Uma das crianças cegas recebeu estimulação constante e especializada (ECE), ou seja, realizada por profissionais especializados na estimulação de crianças deficientes visuais e estava matriculada na sala de cinco anos. A outra criança recebeu apenas estimulação assistemática (EA), ou seja, realizada eventualmente, e estava matriculada na sala do maternal. No presente trabalho, a criança cega que recebeu apenas estimulação assistemática foi designada HEA, e a criança cega que recebeu estimulação constante e especializada foi designada LECE.

Uma criança vidente pertencente à sala de cada uma das crianças cegas foi selecionada. Na sala do maternal, a criança vidente selecionada foi $D$, com três anos e oito meses, e, na sala de cinco anos, foi S, com cinco anos e onze meses. As características das interações sociais de D e $\mathrm{S}$ foram comparadas com as características das crianças cegas. O critério para escolha dessas crianças videntes foi o menor número de faltas na caderneta da professora.

A criança cega HEA era um menino com cinco anos de idade com cegueira (retinopatia da prematuridade). HEA passou os primeiros meses de sua vida hospitalizado e, com um ano e seis meses, foi adotado por um casal que também tinha mais quatro filhos adotivos que apresentavam diferentes necessidades educacionais especiais. Aos três anos de idade, HEA começou a frequentar a Associação de Pais e Amigos dos Excepcionais (APAE) de sua cidade. No início da pesquisa, fazia um ano e seis meses que HEA havia deixado a APAE e começado a frequentar a escola regular. A mãe informou que HEA frequentou, por alguns meses, uma associação para deficientes visuais em outra cidade. Essa criança manifestava comportamentos estereotipados e autoestimulatórios, não falava e nem interagia com os colegas, bem como se afastava quando esses se aproximavam.

A criança cega LECE era um menino cego (catarata congênita) com cinco anos e nove meses que frequentava a sala de cinco anos (alunos com idades entre cinco e seis anos). Aos três anos de idade, LECE começou a frequentar a sala de recursos em uma escola regular onde the ensinavam a leitura e escrita em Braille, além de outras habilidades. Aos quatro anos, ainda na sala de recursos, começou a frequentar a sala regular de outra escola. Frequentava também treino de futebol e natação há dois anos e uma associação que realizava estimulação, principalmente de orientação e mobilidade, há um ano.

\section{Coleta de dados}

Inicialmente foram realizadas visitas às escolas para que as crianças se acostumassem com a presença da pesquisadora e do equipamento utilizado. Em seguida, foram organizadas situações nas quais todas as crianças de cada sala brincassem livremente no ambiente escolar com os brinquedos fornecidos pela escola. Os desempenhos das crianças foram videogravados, empregando-se o registro de grupo focal, neste caso, com o foco na criança cega. Para tratamento e análise dos dados, foram considerados os registros de duas sessões que totalizaram 37 minutos de registro, cada uma delas com aproximadamente 19 minutos.

\section{Tratamento de dados}

O procedimento de tratamento dos dados teve início com o recorte dos episódios de interação. Os critérios para identificação de um episódio foram: (a) toda iniciativa de interação que envolvesse a criança (protagonista ou alvo da iniciativa) cega ou vidente foi considerada o início de um episódio de interação (unidade de análise), ou seja, o início do episódio consistia na aproximação de uma criança (cega ou vidente), formando uma díade; (b) o episódio terminava quando o fluxo de ações entre a díade era interrompido (Souza, 2006) com a aproximação de um terceiro participante, ou seja, quando a composição social do grupo era alterada, formando uma nova díade (Pedrosa \& Carvalho, 2005).

Foram organizados protocolos de transcrição dos episódios nos quais eram identificadas as peculiaridades das interações e das iniciativas de interação das crianças cegas e das crianças videntes. Os episódios de interações registrados para análise foram identificados por dois juízes e, somente quando havia concordância entre os dois juízes, as interações eram registradas como um episódio. O critério para seleção dos juízes foi que deveriam ser alunos de iniciação científica ou de pós-graduação com familiaridade com os estudos sobre interação social. Os juízes assistiram juntos às cenas e acordaram se o conjunto de ações deveria ou não ser considerado um episódio interativo de acordo com os critérios estabelecidos no estudo.

Nos protocolos de transcrição, foram utilizados três conjuntos de categorias, são eles: (a) parceiro(s) da interação; (b) protagonista do início e do término da interação; e (c) qualidade da interação. Referente ao primeiro conjunto, parceiro(s) da interação, foram elaboradas as seguintes categorias: (a) interação com professora; (b) interação com criança mediada pela professora; (c) interação espontânea com criança; e (d) não interação.

No que diz respeito ao segundo conjunto, protagonista do início e do término da interação, foram elaboradas duas categorias e suas respectivas subcategorias: 1) Inicia- 
dora/Receptora: (a) Iniciadora; (b) Receptora; (2) Término da Interação: (a) Criança Cega; (b) Colega ou Professora.

Em relação ao terceiro conjunto, qualidade da interação, foi utilizado o sistema de categorias e subcategorias elaborado por Souza (2006) especificamente para classificação dos episódios de interação: (a) Modos de Interação (simples, compartilhada simples e compartilhada complexa) e (b) Tipos de Interação (agonística, amistosa e cooperativa). Essas categorias analisam a qualidade das interações registradas, em termos de complexidade dos episódios (referente à categoria Modos de Interação) e tipo de afeto gerado nos indivíduos envolvidos nesses episódios (referente à categoria Tipos de Interação). Em outras palavras, teve como objetivo saber como (modos) acontece e identificar o conteúdo (tipos) da interação, respectivamente. Na Tabela 1 , pode-se visualizar o sistema da classificação proposto por Souza (2006).

Tabela 1. Classificação de episódios de interação social (Souza, 2006)

\begin{tabular}{|c|c|c|c|}
\hline CATEGORIAS & SUB-CATEGORIAS & DESCRIÇÃO & EXEMPLOS \\
\hline \multirow{3}{*}{$\begin{array}{c}\text { Modo } \\
\text { de } \\
\text { interação } \\
\text { (Complexidade) }\end{array}$} & SIMPLES & $\begin{array}{l}\text { Caracteriza-se por uma troca de } \\
\text { comportamentos socialmente dirigidos }{ }^{1} \\
\text { entre os parceiros de um determinado } \\
\text { episódio interativo sem que essas } \\
\text { ações regulem o comportamento do(s) } \\
\text { envolvidos(s). }\end{array}$ & $\begin{array}{l}\text { A, sentado no chão, manipula alguns } \\
\text { objetos. B caminha na direção de A e } \\
\text { estende-lhe um brinquedo. A olha para } \\
\text { B e para o brinquedo oferecido. B sai } \\
\text { de cena com o brinquedo e A volta a } \\
\text { brincar com os objetos no chão. }\end{array}$ \\
\hline & $\begin{array}{l}\text { COMPARTILHADA } \\
\text { SIMPLES }\end{array}$ & $\begin{array}{l}\text { Ocorre quando há ações recíprocas } \\
\text { entre os parceiros de um determinado } \\
\text { episódio e essas ações são reguladas } \\
\text { por um ou mais indivíduos envolvidos } \\
\text { na interação, ou seja, as ações do(s) } \\
\text { participante(s) são reguladas pelos } \\
\text { comportamentos do(s) outro(s). }\end{array}$ & $\begin{array}{l}\text { A estende um bonequinho na direção } \\
\text { de } B \text {. B pega o objeto e olha para } A \text {. } \\
\text { A sai de cena enquanto } B \text { analisa o } \\
\text { bonequinho que ganhou de } A \text {. }\end{array}$ \\
\hline & $\begin{array}{l}\text { COMPARTILHADA } \\
\text { COMPLEXA }\end{array}$ & $\begin{array}{l}\text { Ocorre quando a ação recíproca entre } \\
\text { os parceiros envolvidos numa interação } \\
\text { possui regulação e significado } \\
\text { compartilhado. }\end{array}$ & $\begin{array}{l}\text { A e B estão sentados de frente um } \\
\text { para o outro, cada um com uma } \\
\text { pazinha. Entre A e B existe um } \\
\text { baldinho e ambos enchem-no de } \\
\text { areia utilizando as pazinhas. A coloca } \\
\text { uma pá de areia e B segue, colocando } \\
\text { uma pá também, até que o baldinho } \\
\text { fica cheio de areia. }\end{array}$ \\
\hline \multirow{3}{*}{$\begin{array}{c}\text { Tipo } \\
\text { de } \\
\text { interação } \\
\text { (Tipo de afeto) }\end{array}$} & AGONÍSTICA & $\begin{array}{l}\text { Ocorre quando o comportamento } \\
\text { socialmente dirigido de pelo menos } \\
\text { um dos indivíduos envolvidos no } \\
\text { episódio interativo resulta em aflição, } \\
\text { desagrado ou sofrimento de outro(s) } \\
\text { indivíduo(s) envolvido(s) no episódio } \\
\text { (DEL PRETTE, BRANCO, CENEVIVA, } \\
\text { ALMEIDA\&ADES,1986; GIL, ALMEIDA } \\
\text { \& NASCIMENTO, 2001). }\end{array}$ & $\begin{array}{l}\text { Disputa de objetos puxando-os } \\
\text { das mãos de outra criança; bater } \\
\text { em outra criança com um objeto; } \\
\text { empurrar a outra criança. }\end{array}$ \\
\hline & AMISTOSA & $\begin{array}{l}\text { Ocorre quando o comportamento } \\
\text { socialmente dirigido de pelo menos um } \\
\text { dos indivíduos envolvidos no episódio } \\
\text { interativo resulta em acolhimento e } \\
\text { ou demonstração de afeto de outro(s) } \\
\text { indivíduo(s) envolvido(s) no episódio. }\end{array}$ & $\begin{array}{l}\text { Oferecer objeto estendendo-o em } \\
\text { direção a outra criança; mostrar objeto } \\
\text { a outra criança; imitar reproduzindo } \\
\text { comportamentos de outra criança } \\
\text { envolvendo o uso de objeto; acariciar } \\
\text { outra criança. }\end{array}$ \\
\hline & COOPERATIVA & $\begin{array}{l}\text { Ocorre quando os comportamentos } \\
\text { socialmente dirigidos de pelo menos } \\
\text { dois indivíduos do grupo interativo } \\
\text { completam-se entre si na consecução } \\
\text { de um objetivo comum (DEL PRETTE } \\
\text { et al.,1986). }\end{array}$ & $\begin{array}{l}\text { Alternância de papéis utilizando o } \\
\text { objeto como mediador ("dar papá" } \\
\text { para outra criança); abraço mútuo. } \\
\text { As interações desse tipo foram } \\
\text { computadas como amistosas, } \\
\text { mas, em função de sua relevância, } \\
\text { obtiveramum tratamento diferenciado. }\end{array}$ \\
\hline
\end{tabular}

1 De acordo com Souza (2006), adaptado de Mueller \& Brenner (1977), o Comportamento Socialmente Dirigido (CSD) é a unidade social mínima a ser estabelecida como suporte objetivo para observação da interação. 


\section{Análise de dados}

Foi utilizado o Pacote Estatístico para Ciências Sociais - SPSS-WIN, versão 15, para realizar o Teste de Independência do Qui-Quadrado. Para as análises das características das interações, foram compostos dois grupos: (a) HEA (criança cega) e D (criança vidente); e (b) LECE (criança cega) e S (criança vidente). Foi considerado ainda um terceiro grupo para efeito de análise, organizado com os resultados obtidos para cada uma das crianças cegas.

\section{Resultados}

No contexto das interações entre crianças, foram consideradas as características das iniciativas, do recebimento das iniciativas e do término das interações, bem como do conteúdo e de sua qualidade. Essas características são descritas nas categorias a seguir.

Em relação à categoria Iniciadora/Receptora, na Figura 1, foram comparadas as frequências das iniciativas de interação dos dois grupos de crianças: grupo 1 (HEA e D) e grupo 2 (LECE e S); e foram comparados os resultados obtidos por HEA e LECE.

No grupo 1, com base nos resultados do teste de Qui-quadrado, as diferenças foram significativas $\left(\chi^{2}=15,37\right.$, $p<0,05)$, pois as crianças comportaram-se de maneira diferente em relação a iniciar as interações ou receber as iniciativas. HEA não iniciou nenhuma interação e foi apenas receptora (100\%), ao contrário de D, criança vidente, que realizou mais iniciativas de interação $(76,2 \%)$ do que foi receptora $(23,8 \%)$.

No grupo 2, não foi observada diferença estatisticamente significativa $\left(\chi^{2}=3,53, p>0,05\right)$, pois as duas crianças foram mais receptoras do que iniciadoras de interação, sendo que a porcentagem de recepção de iniciativas de LECE (64\%) foi um pouco superior à de S (50,5\%).

O teste de independência do qui-quadrado acusou diferença significativa ao se comparar os resultados das duas crianças cegas, ambas mais receptoras do que iniciadoras

\section{INICIADORA/RECEPTORA}

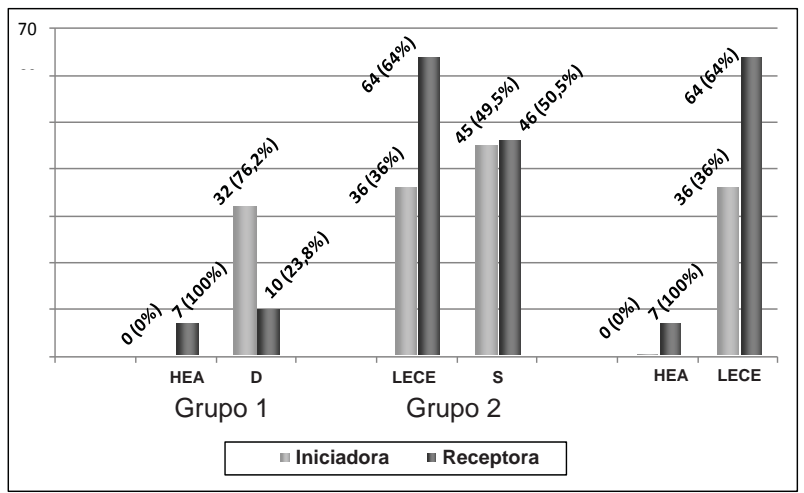

Figura 1: Frequências dos escores brutos das iniciativas de interação para os dois grupos de crianças e para HEA e LECE. de interação $\left(\chi^{2}=3,20, p>0,05\right)$. A criança cega HEA não realizou nenhuma iniciativa de interação, enquanto que a criança cega LECE apresentou 36\% de iniciativas de interação.

No que diz respeito ao término das interações, os resultados apresentados na Figura 2 indicam que, no grupo 1 , a criança vidente $D$ encerrou mais episódios de interação do que a criança cega HEA. Com base nas análises estatísticas, essa diferença foi significativa $\left(\chi^{2}=6,81, p<0,05\right)$. Além disso, a criança cega teve maior número de episódios de interação encerrados pela professora $(85,7 \%)$ do que por ela mesma (14,3\%), ao contrário da criança vidente, que encerrou $(66,7 \%)$ mais episódios de interação do que teve esses encerrados por outros indivíduos.

Considerando-se os resultados do teste de independência qui-quadrado, verifica-se que o grupo 2 apresentou diferença significativa no comportamento das crianças $\left(\chi^{2}=\right.$ $12,85, p<0,05)$ : a criança cega LECE encerrou menos interações (47\%) do que a criança vidente $S(72,5 \%)$, bem como teve suas interações mais encerradas pelo colega ou professora (53\%) do que teve a criança vidente $(27,5 \%)$. Ressalta-se que a diferença entre encerrar o episódio de interação ou esse ser encerrado pelo colega ou professora não foi tão desproporcional para a criança cega como foi para a criança vidente, que apresentou uma porcentagem de $72,5 \%$ de términos de interação.

Ao se comparar os resultados obtidos pelas crianças cegas, verificou-se que tiveram seus episódios de interação predominantemente encerrados pelos colegas ou professora, sem diferença significativa quanto ao término da interação $\left(\chi^{2}=2,83, p>0,05\right)$.

\section{TÉRMINO DA INTERAÇÃO}

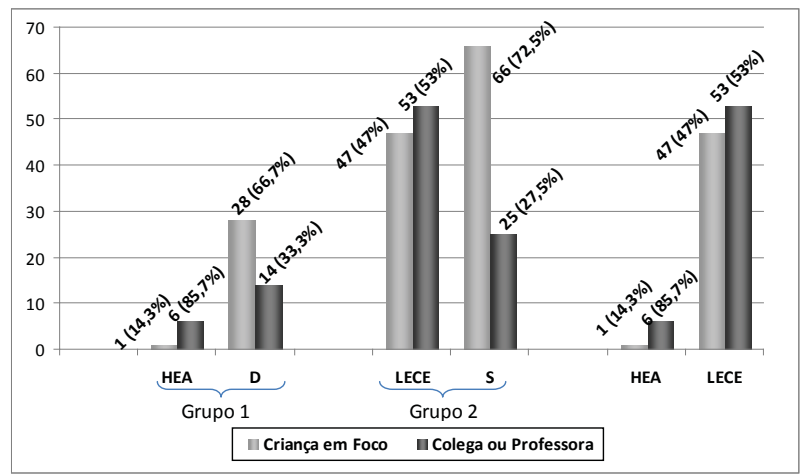

Figura 2: Frequências dos escores brutos das categorias dos términos das interações para os dois grupos de crianças e para HEA e LECE.

A distribuição da frequência de interações referentes aos parceiros de interação (interação com professora, interação criança professora, interação criança espontânea e não interação) pode ser verificada na Figura 3. No grupo 1, foram encontradas diferenças estatisticamente significativas $\left(\chi^{2}=\right.$ $53,62, p<0,05)$ : as crianças comportaram-se diferentemente em relação aos parceiros de interação. A criança cega HEA não participou de nenhuma interação com colegas, enquan- 
to que a criança vidente $\mathrm{D}$ interagiu predominantemente com outras crianças, apresentando apenas uma interação com a professora. Ademais, HEA foi a única criança que pontuou na categoria não interação.

No grupo 2, não foi verificada diferença significativa $\left(\chi^{2}=4,67, p>0,05\right)$, já que as duas crianças pontuaram mais alto na categoria interação criança espontânea. Destaca-se que a criança vidente $\mathrm{S}$ apresentou apenas interações espontâneas com colegas (100\%), enquanto a criança cega LECE, além de interagir espontaneamente com colegas (95\%), interagiu também, em baixa porcentagem, com a professora (3\%) e com colega mediada pela professora (2\%).

Ainda com relação à Figura 3, comparando-se os resultados das duas crianças cegas, foi encontrada diferença bastante significativa no que diz respeito aos parceiros de interação $\left(\chi^{2}=98,34, p<0,05\right)$. A criança cega HEA não interagiu com colegas e pontuou alto $(56,3 \%)$ na categoria não interação. O contrário foi observado para a criança cega LECE, que apresentou uma porcentagem de 95\% de ocorrências na categoria interação criança espontânea e não pontuou na categoria não interação.

\section{PARCEIROS DE INTERAÇÃO}

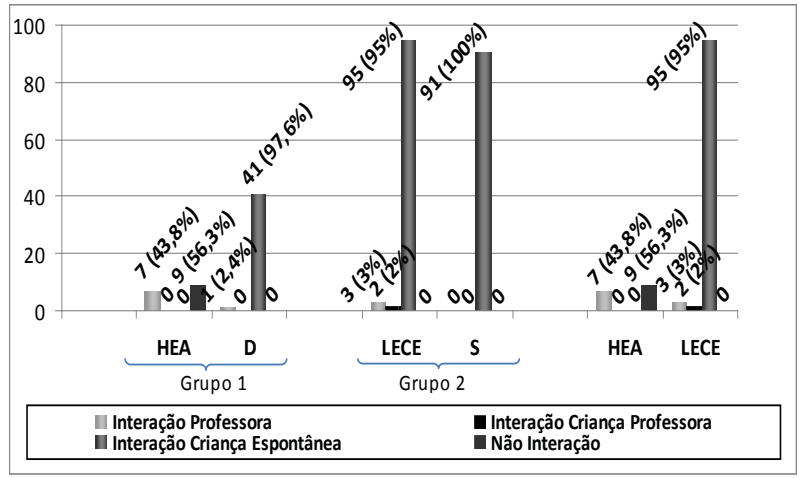

Figura 3: Frequências dos escores brutos das categorias de parceiros de interações para os dois grupos de crianças e para HEA e LECE.

Em relação aos tipos de interação, na Figura 4, observa-se a frequência das interações agonísticas e amistosas. As crianças do grupo 1 diferiram significativamente em relação ao tipo de interação predominante $\left(\chi^{2}=8,45\right.$, $p<0,05)$. A criança cega HEA apresentou interações mais agonísticas do que amistosas. O contrário foi verificado para a criança vidente $D$, que teve a maioria de suas interações (81\%) classificadas como amistosas. É necessário destacar que, para a criança HEA, a interação era classificada como agonística em situações nas quais a professora solicitava que ele apresentasse determinados desempenhos e não era atendida. Um exemplo de episódio classificado como de interação agonística era quando a professora entregava objetos para HEA, e ele soltava o objeto assim que a professora o entregava.
No que diz respeito à comparação da criança cega LECE com a criança vidente S (grupo 2), os dados apresentados na Figura 4 sugerem que ambas se comportaram praticamente do mesmo modo em relação ao conteúdo (tipo) da interação $\left(\chi^{2}=0,25, p>0,05\right)$. A criança cega LECE e a criança vidente $S$ apresentaram mais interações amistosas (94\% e 95,6\%, respectivamente) do que agonísticas.

\section{TIPOS DE INTERAÇÃO}

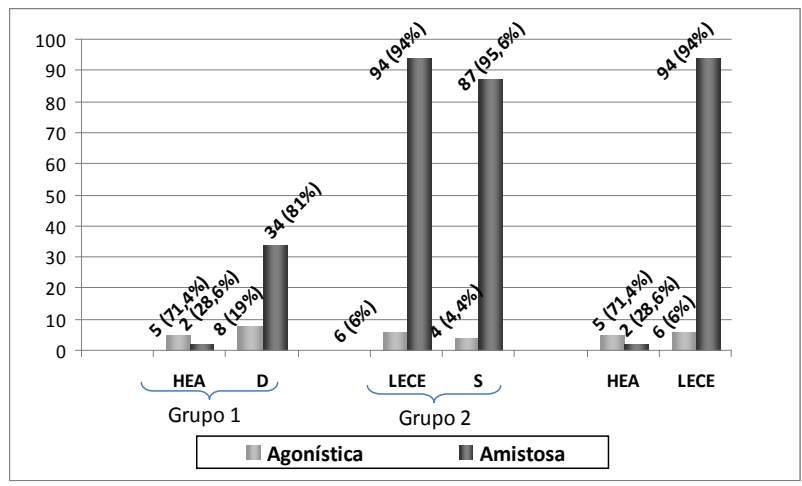

Figura 4: Frequências dos escores brutos das interações agonísticas e amistosas para os dois grupos de crianças e para HEA e LECE.

Em um enfoque diferencial, a discrepância entre os resultados das duas crianças cegas com relação aos tipos de interação foi muito acentuada, estatisticamente significativa $\left(\chi^{2}=30,36, p<0,05\right)$. As interações da criança cega HEA foram, em sua maioria, agonísticas $(71,4 \%)$, enquanto que as da criança cega LECE foram predominantemente classificadas como amistosas (94\%).

As frequências de ocorrência das interações amistosas cooperativas ou amistosas não cooperativas podem ser visualizadas na Figura 5. Nessas categorias, não houve diferença estatisticamente significativa na comparação das crianças cegas e videntes e entre os resultados obtidos pelas duas crianças cegas. Todas as crianças, grupo $1\left(\chi^{2}=\right.$ $0,35, p>0,05)$, grupo $2\left(\chi^{2}=0,20, p>0,05\right)$ e as duas crianças cegas $\left(\chi^{2}=2,53, p>0,05\right)$, tiveram a maioria de suas interações amistosas classificadas como Não Cooperativas. Com exceção de HEA, as crianças D (4,8\%), LECE (27\%) e S $(24,2 \%)$ apresentaram interações amistosas cooperativas, mesmo que em baixa proporção. Verifica-se que a criança cega LECE apresentou uma porcentagem maior nas interações amistosas cooperativas $(27 \%)$ do que sua colega vidente S (24,2\%).

Em se tratando do modo como ocorrem as interações sociais, a Figura 6 apresenta as frequências das interações simples, compartilhada simples e compartilhada complexa. Os participantes dos dois grupos (1 e 2), bem como as crianças cegas entre si, apresentaram diferenças estatisticamente significativas na distribuição de episódios de modo de interação. 


\section{COOPERATIVA}

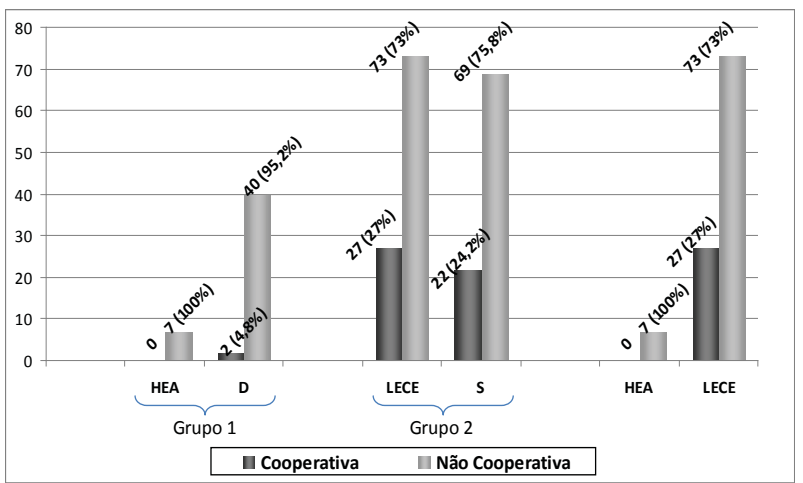

Figura 5: Frequências dos escores brutos das interações amistosas cooperativas e não cooperativas para os dois grupos de crianças e para HEA e LECE.

No grupo 1, ao se comparar o modo de interações da criança cega HEA com o da criança vidente, a diferença foi significativa $\left(\chi^{2}=7,84, p<0,05\right)$. HEA apresentou apenas 0 modo de interação compartilhada simples (100\%), enquanto que a criança vidente pontuou diferentemente nos três modos: simples $(21,4 \%)$, compartilhada complexa $(35,7 \%)$ e compartilhada simples $(42,9 \%)$.

No segundo grupo, $76 \%$ das interações da criança cega LECE foram classificadas como compartilhada comple$x a$, porcentagem superior à da criança vidente $\mathrm{S}$, que foi de $50,5 \%$. Com base nas análises, essa diferença foi estatisticamente significativa $\left(\chi^{2}=13,46, p<0,05\right)$. As duas crianças, LECE e S, também apresentaram interações simples $(10 \%$ e $18,7 \%$ respectivamente) e compartilhada simples (14\% e $30,8 \%$, respectivamente).

A realização do teste de independência qui-quadrado indicou diferença significativa entre os resultados das crianças cegas, apresentados na Figura $6\left(\chi^{2}=30,67, p<0,05\right)$. A criança cega HEA apresentou apenas interações Com-

\section{MODOS DE INTERAÇÃO}

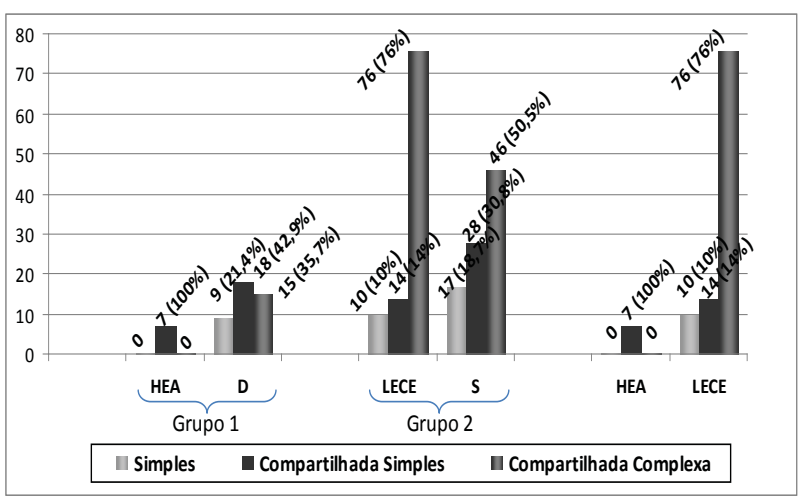

Figura 6: Frequências dos escores brutos do modo de interação (simples, compartilhada simples e compartilhada complexa) para os dois grupos de crianças e para HEA e LECE. partilhada Simples (100\%). O contrário foi verificado para a criança LECE, que teve suas interações distribuídas nos três modos: simples (10\%), compartilhada simples (14\%) e compartilhada complexa (76\%). É importante destacar que o modo de interação predominante no comportamento da criança cega LECE foi compartilhada complexa.

Diante dos resultados obtidos pelas análises da frequência de ocorrência das categorias descritas na Tabela 1 e apresentadas nas Figuras, foi possível verificar algumas particularidades das interações das crianças participantes do estudo. As particularidades foram encontradas tanto na comparação entre as características das interações entre crianças cegas e videntes como também na comparação do desempenho das crianças cegas entre elas.

\section{Discussão}

Os resultados obtidos na caracterização das interações sociais de crianças cegas com diferentes histórias de atenção e educação especializada e com crianças videntes em salas regulares de educação infantil parece indicar a importância de considerar tanto a abordagem comparativa como o enfoque diferencial. As crianças participantes deste estudo compartilharam algumas características das interações na sala de aula e diferenciaram-se umas em relação a outras, fosse a comparação entre crianças cegas e videntes ou entre crianças cegas.

Ao tratar da comparação das características das interações sociais entre as crianças cegas e as videntes, é importante discutir algumas diferenças encontradas na ocorrência das categorias de interação. Referente ao comportamento de iniciar ou receber interações, as crianças cegas foram mais receptoras de iniciativas de interações de outras crianças do que iniciadoras se comparadas às crianças videntes. Esse resultado corrobora aqueles obtidos por Crocker e Orr (1996), que encontraram diferenças na frequência com que as crianças deficientes visuais iniciaram uma interação ou foram receptoras de uma iniciação; essas crianças foram na maior parte do tempo receptoras de uma interação.

No que diz respeito ao término das interações, as crianças videntes encerraram um número maior de episódios de interações do que tiveram suas interações encerradas por colegas ou professora. O contrário foi observado para as crianças cegas, que tiveram suas interações encerradas, com maior frequência, pelos colegas ou professora do que por elas mesmas. Em relação aos parceiros-alvo de interação, os resultados da criança cega LECE foram semelhantes aos obtidos pela criança vidente. Entretanto, as diferenças entre os resultados da criança cega HEA e da criança vidente foram muito acentuadas. $\mathrm{O}$ mesmo pode ser observado em relação aos tipos de interação.

Em relação à qualidade das interações, de acordo com a complexidade (modos) e afeto gerado no parceiro (tipo), um aspecto destacou-se pelo fato de que, para todas as crianças, a grande maioria das interações foi classificada 
como não cooperativa. No entanto, mesmo com uma porcentagem baixa, as crianças apresentaram interação cooperativa, com exceção de HEA, que não apresentou esse tipo de interação. Destaca-se que a criança cega LECE apresentou uma porcentagem maior nas interações amistosas cooperativas do que sua colega vidente (S). Além disso, a criança cega LECE teve mais interações compartilhadas complexas do que a criança vidente.

Ao contrário do que apresenta a literatura, LECE não apresentou brincadeiras exploratórias ou repetitivas, mas realizou brincadeiras manipulativas, utilizando os brinquedos de forma funcional e criativa. Essa criança passou a maior parte do tempo registrado criando brincadeiras de faz de conta. Em vários momentos, registrados em vídeo, LECE ditou o conteúdo da brincadeira (por exemplo, Casinha, Trabalhar fora e Polícia e ladrão) e designou papéis às crianças videntes, que o imitavam participando do faz de conta. Esse resultado corrobora aqueles apresentados em alguns estudos (Hueara e cols., 2006; Silveira, Loguercio, \& Sperb, 2000) que afirmam que as crianças deficientes visuais são hábeis para brincar de faz de conta, representando papéis, criando cenas e estabelecendo regras. Dessa forma, pode-se afirmar, com base nos resultados, que crianças cegas que receberam estimulação constante e especializada provavelmente serão capazes de brincar de faz de conta e criar brincadeiras imaginativas envolvendo jogos de papéis, tão bem quanto ou até melhor que as crianças videntes.

No geral, as características das interações de LECE, que recebeu estimulação constante e especializada, estavam mais próximas às da criança vidente. Entretanto, ao se comparar as características de interação da criança cega HEA, que recebeu estimulação assistemática, com as da criança vidente, foram encontradas discrepâncias acentuadas.

Em se tratando especificamente da comparação dos resultados das duas crianças cegas, verifica-se, nesse estudo, que a maioria das características das interações sociais apresentadas foi significativamente diferente entre elas. Ao contrário de HEA, cujas interações ocorreram exclusivamente por iniciativa do outro, um terço dos episódios de interação envolvendo LECE foram por iniciativa dele. Em relação ao término das interações das duas crianças, um resultado aparentemente contraditório indica a importância de se adotar os enfoques comparativos e diferenciais no atual desenvolvimento dos estudos sobre interação social de crianças cegas. Nos resultados obtidos neste estudo, foram identificadas semelhanças e divergências no término das interações; ambas tiveram suas interações mais encerradas por colegas ou professoras do que por elas mesmas. No entanto, a criança LECE encerrou mais interações do que a criança HEA. Na seleção de parceiros de interação, LECE apresentou uma porcentagem de 95\% de interações com colegas, enquanto a criança cega HEA participou exclusivamente de interações sociais com a professora.

Um dos resultados encontrados no presente trabaIho, que contradiz a literatura, diz respeito ao alvo das interações. Ao contrário do que foi observado no estudo de
Crocker e Orr (1996), que verificaram diferenças nos alvos de interações de crianças deficientes visuais que iniciavam mais interações com o professor do que com crianças videntes, no presente trabalho, apenas a criança cega que recebeu estimulação assistemática interagiu somente com a professora.

No que diz respeito ao conteúdo da interação, a criança cega LECE apresentou frequência acentuadamente maior de interações amistosas quando comparada às interações agonísticas, e todas as interações de LECE com a professora foram classificadas como amistosas. Entretanto, a criança cega HEA teve a maioria de suas interações com a professora classificadas como agonísticas.

As conclusões de Erwin (1993) reforçam os resultados obtidos no presente estudo apenas para o caso da criança cega que recebeu estimulação assistemática. Esse autor verificou que crianças deficientes visuais gastavam mais tempo em brincadeiras solitárias ou interagindo com adultos do que com seus colegas videntes. O contrário foi verificado para a criança cega LECE, que passou a maior parte do tempo registrado em companhia dos colegas. Além disso, essa criança teve a maioria de suas interações classificadas como Compartilhada Complexa, apresentando regulação e significado compartilhado nas brincadeiras, enquanto a criança cega que recebeu estimulação assistemática não apresentou esse modo de interação.

De modo geral, nas categorias Iniciadora/Receptora e Término de Interação, os resultados corroboraram os estudos apresentados na presente pesquisa, pois as crianças cegas foram mais receptoras do que iniciadoras e tiveram suas interações mais encerradas por outros do que por elas mesmas. No entanto, ao se considerar a qualidade da interação (Tipos de Interação e Modos de Interação) e os parceiros de interação, foram verificadas diferenças no que diz respeito aos resultados encontrados pelos pesquisadores citados no presente trabalho. Isso é mais evidente ao se analisar os resultados da criança cega que recebeu estimulação constante e especializada, a qual apresentou desempenhos comparáveis aos da criança vidente.

Com base nesses resultados, verifica-se que o fato de a criança cega receber ou não receber estimulação especializada produz características diferentes nas interações das quais participa, o que indica a necessidade de cuidado adicional ao se generalizar para a população de crianças cegas os resultados alcançados nos estudos com amostras restritas. Ressalta-se que, se a criança possui uma deficiência visual, isso não significa que ela terá, obrigatoriamente, entraves ao desenvolvimento cognitivo, emocional e social. No entanto, as formas de interação, comunicação e construção social de significados serão determinantes para o seu desenvolvimento social e sua aprendizagem. A criança cega provavelmente não terá dificuldades para aprender e interagir se Ihe for propiciada estimulação em tempo e um ambiente rico em experiências onde ela possa desenvolver suas capacidades.

No presente estudo, observou-se que, recebendo estimulação constante e especializada, a criança cega 
apresenta comportamentos semelhantes ao de uma criança vidente no ambiente escolar. É possível supor que, havendo apenas comprometimento visual, as crianças cegas que recebem esse tipo de estimulação possam passar mais tempo interagindo com os colegas do que com adultos e menos tempo em brincadeiras solitárias, diferentemente do que a literatura apresenta.

É preciso destacar que parece legítimo supor que, independente do nível de deficiência, se a criança tem ou não deficiências adicionais, são a qualidade e a continuidade da atenção e dos processos educativos que propiciariam a aquisição de novos desempenhos e a superação de alguns dos limites impostos pela relação entre a deficiência e o ambiente. O curso do desenvolvimento social não deve ser determinado tendo por referência a criança vidente, pois ficou evidenciado, nos resultados, que crianças cegas têm particularidades e curso próprio de desenvolvimento. Em contrapartida, os resultados permitem ressaltar as semeIhanças entre os desempenhos das crianças videntes e de uma das crianças cegas.

O objetivo das comparações neste estudo não foi estabelecer uma norma pela qual o repertório das crianças cegas devesse ser pautado, mas descrever características compartilhadas pelas crianças independentemente do acesso visual à informação no contexto de sala de aula, bem como as características que as diferenciam umas das outras, sendo ou não cegas. De modo geral, os resultados deste estudo, embora não permitam generalizações em função da pequena amostra, evidenciam importantes aspectos acerca da interação social de crianças cegas e crianças videntes.

\section{Referências}

Ajuwon, P. M. \& Oyinlade, A. O. (2008). Educational placement of children who are blind or have low vision in residential and public schools: a national study of parents' perspectives. Journal of Visual Impairment \& Blindness, 102 (6), 325-339.

Brambring, M. (2001). Integration of children with visual impairment in regular preschools. Child: Care, Health and Development, 27 (5), 425-438.

Bruno, M. M. G. (1993). Desenvolvimento integral do portador de deficiência visual: da intervenção precoce à integração escolar. Rio de Janeiro: Laramara.

Celeste, M. (2006). Play behaviors and social interactions of a child who is blind: in theory and practice. Journal of Visual Impairment \& Blindness, 100 (2), 75-90.

Celeste, M. (2007). Social skills intervention for a child who is blind. Journal of Visual hnpairnent \& Blindness, 101 (9), 521-533.
Crocker, A. D., \& Orr, R. R. (1996). Social behaviors of children with visual impairments enrolled in preschool programs. Exceptional Children, 62 (5), 451-462.

D'Allura, T. (2002). Enhancing the social interaction skills of preschoolers with visual impairments. Journal of Visual Impairment \& Blindness, 96(9), 577-584.

Erwin, E. J. (1993). Social participation of young children with visual impairment in specialized and integrated environments. Journal of Visual Impairment \& Blindness, 87 (5), 138-142

Gold, D., Shaw, A. \& Wolffe, K. (2010). The social lives of Canadian youth with visual impairments. Journal of Visual Impairment \& Blindness, 104 (7), 431-443.

Hueara, L., Souza, C. M. L., Batista, C. G., Melgaço, M. B. \& Tavares, F. S. (2006). O faz-de-conta em crianças com deficiência visual: identificando habilidades. Revista Brasileira de Educação Especial, 12 (3), 351-368.

Kekelis, L. S. (1997). Peer interaction in childhood: the impact of visual impairment. In S. Z. Sacks, L. S. Kekelis \& R. J. GailordRoss (Orgs.) The development of social skills by blind and visually impaired students: Exploratory studies and strategies (pp. 13-35). New York: American Fundation for the Blind.

Leme, M. E. S. (2003). A representação da realidade em pessoas cegas desde o nascimento. Dissertação de Mestrado, Programa de Pós-Graduação em Educação, Universidade de Campinas, Campinas - SP.

Pedrosa, M. I. \& Carvalho, A. M. A. (2005). Análise qualitativa de episódios de interação: uma reflexão sobre procedimentos e formas de uso. Psicologia: Reflexão e Crítica, 18 (3), 431-442.

Roe, J. (2008). Social inclusion: meeting the socio-emotional needs of children with vision needs. British Journal of Visual Impairment, 26 (2), 147-158.

Santos, F. D. (2004). A aceitação e o enfrentamento da cegueira na idade adulta. Dissertação de Mestrado, Programa de PósGraduação em Educação Especial, Universidade Federal de São Carlos, São Carlos - SP.

Silveira, A. D., Loguercio, L. C. \& Sperb, T. M. (2000). A brincadeira simbólica de crianças deficientes visuais pré-escolares. Revista Brasileira de Educação Especial, 6 (1), 133-146.

Souza, I. C. (2006). Características das interações entre bebês mediadas por diferentes estruturas de brinquedos. Monografia de Iniciação Científica, Departamento de Psicologia, Universidade Federal de São Carlos, São Carlos, SP.

Warren, D. H. (1994). Blindness and children: An individual differences approach. EUA: Cambridge University Press. 
Recebido em: 01/11/2011

Reformulado em: 11/10/2012

Aprovado em: 25/10/2012

Sobre as autoras

Maria Luiza Pontes de França-Freitas (mluizapf@yahoo.com.br)

Doutora em Psicologia (PPGPSI - UFSCAR) e Mestre em Educação Especial (PPGEES - UFSCAR).

Endereço para correspondência com o editor: : Universidade Federal de São Carlos, Centro de Educação e Ciências Humanas, Departamento de Psicologia. Rodovia Washington Luiz, Km 235 - Cx. Postal 676, Monjolinho, São Carlos, SP, Brasil - CEP: 13565-905.

Maria Stella Coutinho de Alcântara Gil (stellagil@uol.com.br)

Professora Doutora do Departamento de Psicologia e do PPGEES da Universidade Federal de São Carlos (UFSCAR).

Endereço para correspondência: : Avenida Senador Julio Cesar Leite, 957, Condomínio Viña Del Mar, Casa 15, Aracaju, Sergipe - CEP: 49037-580.

Apoio financeiro da Coordenação de Aperfeiçoamento de Pessoal de Nível Superior (CAPES).

Trabalho resultante de dissertação de mestrado da primeira autora. 